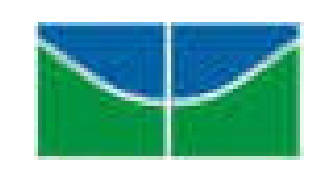

Universidade de Brasília

Centro de Excelência em Turismo

\title{
VIGILÂNCIA SANITÁRIA: PROMOÇÃO DA SAÚDE CRIANDO INSTRUMENTOS PARA QUALIFICAÇÃO DO MANIPULADOR DE ALIMENTOS NO DISTRITO FEDERAL
}

Admilson Vargas

Monografia apresentada ao Centro de Excelência em Turismo da Universidade de Brasília como requisito parcial para a obtenção do certificado de Especialista em Qualidade em Alimentos. Orientadora: Lucianne Cardoso 
Á Orientadora Lucianne Cardoso pela dedicação. Aos colegas da Diretoria de Vigilância Sanitária do Distrito Federal Laércio, Rodrigo, Denise e Maria das Graças, pelo apoio. Aos familiares Maria de Fátima, Marisa, Heloísa e Rubens pela paciência. 
Entre os que destroem a lei e os que observam não há neutralidade possível.

Rui Barbosa, Jurista Brasileiro

(1849-1923) 


\section{RESUMO}

Neste trabalho desenvolveu-se pesquisa bibliográfica sobre o papel da Vigilância Sanitária sob o enfoque promoção da saúde. Observase que, ao governo, por intermédio da Vigilância Sanitária, cabe zelar pela qualidade dos serviços direta ou indiretamente relacionados à saúde e pela qualidade dos produtos expostos ao consumo da população, além de se configurar em um serviço ativo e permanente de defesa e proteção da saúde. Promoção da Saúde na área de alimentos deve ser entendido como o conjunto de ações dos setores público e privado, de individuo e grupos, que tenham por finalidade garantir a segurança dos alimentos. Portanto, constitui papel do Estado emitir leis, fiscalizar e educar.Cabe às organizações privadas instituir programas e implantar sistemas que atendam à legislação e propiciem a melhoria da qualidade. O treinamento de funcionários é elemento chave para garantir alimentos com adequado padrão higiênico sanitário, porque as doenças transmitidas pelos alimentos representam considerável grau de morbidade e mortalidade na população maioria dos casos é de origem microbiana e deve-se à manipulação inadequada. Baseado nos estudos teóricos sobre Vigilância Sanitária sob o enfoque: promoção da saúde; segurança alimentar; legislação brasileira sobre alimentos; e o manipulador de alimentos, o presente trabalho propõe a criação de um instrumento legal, à Diretoria de Vigilância Sanitária do Distrito Federal, exigindo a obrigatoriedade de treinamentos para manipuladores em estabelecimentos comerciais de alimentos.

Unitermos: Vigilância Sanitária, Promoção da Saúde, Manipulador de alimentos, treinamento, Boas Práticas de Fabricação, Análise dos Perigos e Pontos Críticos de Controle e Segurança Alimentar. 


\section{ABSTRACT}

It was developed work a bibliographical research about the description of the Sanitary Vigilance with the focus health promotion and that suggests a legal instrument for a qualification of the food's manipulation in Distrito Federal, searching for a better and healter quality of food. The hole of the government is to: take care of the quality of services direct or indirectly related to the health and the quality of the product for the population, beside it looks for the protection and defense of the health. Promotion in regards to food must be understood as a group of actions in the private and public areas, individual or in groups, with goal is to provide health food. So that, there must be laws to control and educate people, the private organization must establish programs and create systems that could provide a better quality. The manipulator is very important for the control for the lack of a sustable thermal treatment. The these training course of these employees is extremely important for the quality of food. Health public workers and Sanitary Vigilance food are concerned about the quality of food represent a considerable aspect of morbidity and mortality to the in most of the cases, the cause is microbial and it's because of the inappropriate manipulation. Based on the theoretical studies about Sanitary Vigilancy with the focus: health promotion; food safety laws and manipulation. It suggests as legal instrument for the Management of Sanitary Vigilance of Distrito Federal, asking for training courses for manipulators in places where food is present.

Key-works: Vigilance Sanitary, Promotion of the Health, Manipulator of Victuals, Training, Good Practices of Production, Hazard Analysis and Critical Points of Control and Alimentary Safety. 


\section{SUMÁRIO}

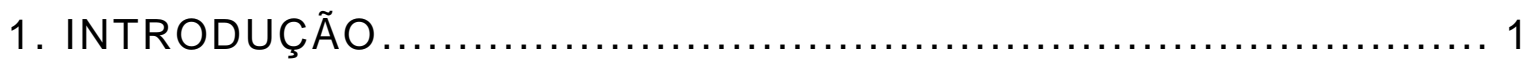

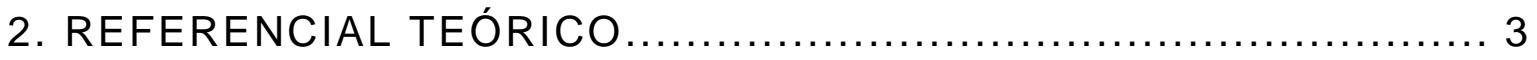

2.1-VIGILÂNCIA SANITÁRIA ...................................... 3

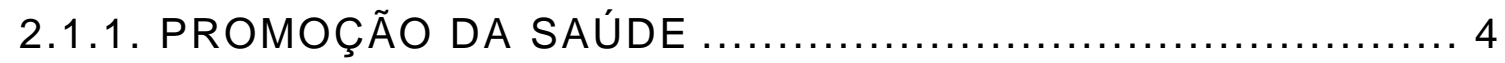

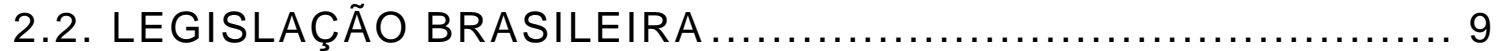

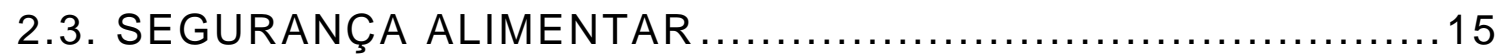

2.4. MANIPULADOR DE ALIMENTOS ........................... 23

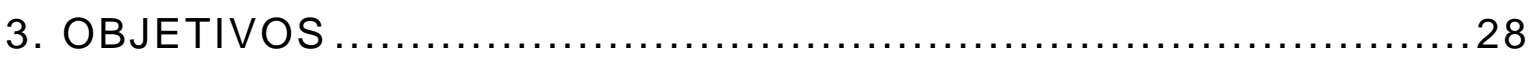

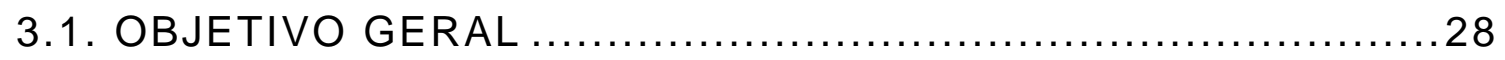

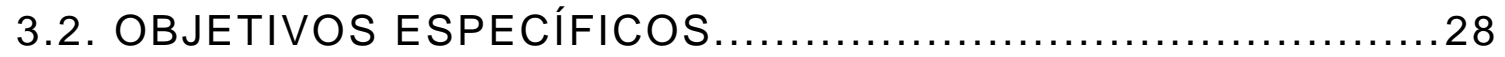

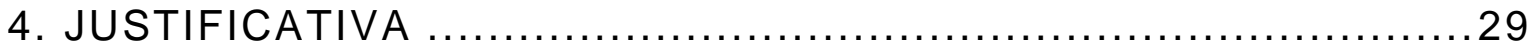

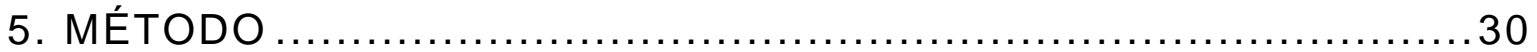

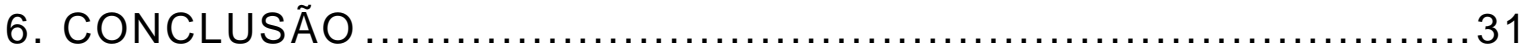

7. RECOMENDAÇÕES ............................................ 32

7.1. MINUTA DE PROJETO MANIPULADOR DE ALIMENTOS DF . 32

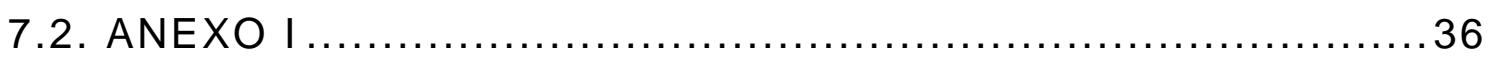

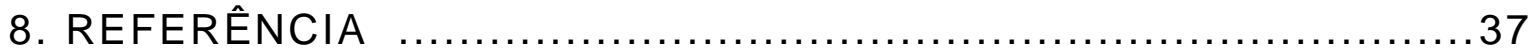




\section{INTRODUÇÃO}

Esta monografia tem como tema a descrição da Vigilância Sanitária sob o enfoque da promoção da saúde e propõe um instrumento para qualificação do manipulador de alimentos no âmbito do Distrito Federal.

Manipuladores de alimentos têm se constituído em permanente preocupação para as empresas de alimentos. A qualidade dos produtos finais depende diretamente de sua habilidade técnica e consciência sanitária, pois alimentos danificados e/ou contaminados podem atingir o consumidor e causar-Ihe danos à saúde, muitas vezes graves.

A indústria procura defender alimentos e consumidores através de rigorosos programas de controle, manutenção e certificação da qualidade,para os quais é fundamental a participação de um manipulador convenientemente treinado.

Atualmente é crescente a preocupação do consumidor brasileiro com relação a qualidade dos alimento e a conseqüente redução dos riscos à saúde. Essa preocupação vai desde o teor de aditivos químicos utilizados no processo de produção, presença de resíduos tóxicos, utilização de plantas e alimentos geneticamente modificados, até a armazenagem e manipulação de produtos e matérias primas.

Destes fatos decorre, a preocupação atual do governo e de agentes econômicos com a segurança alimentar,que,sob o aspecto da inocuidade,se refere à oferta de alimentos livres de agentes 
patogênicos que possam por em risco a saúde do consumidor.Dada a complexidade dos fatores que afetam essa questão, ela deve ser considerada como uma cadeia alimentar: produção, industrialização, distribuição, e consumidor final.

Ao governo por intermédio da Vigilância Sanitária cabe zelar pela qualidade dos serviços direta ou indiretamente relacionados à saúde e pela qualidade dos produtos expostos ao consumo da população, além de se configurar em um serviço ativo e permanente de defesa e proteção da saúde. Suas ações são abrangentes, mas podem ser agrupadas em três campos: as de controle da qualidade dos produtos, desde a produção até o uso: alimentos, medicamentos, cosméticos, produtos de higiene e limpeza, dentre outros; as de controle da qualidade de serviços relacionados à saúde; e as de controle de fatores ambientais que implicam em risco à saúde:

Nas indústrias, centros de distribuição, supermercados e comércio varejista em geral, os maiores problemas em matéria de segurança alimentar estão nos alimentos perecíveis, com contaminação microbiológica elevada, devido a refrigeração inadequada, alto tempo de exposição, condições inadequadas de armazenagem e manipulação imprópria.

Partindo do princípio de que os manipuladores de alimentos
são os maiores veiculadores de perigos biológicos de
contaminação dos alimentos e possível comprometimento
da saúde dos consumidores. A Organização Mundial de
Saúde (1989) relata que mais de $60 \%$ das doenças de
origem alimentar são provocadas por agentes
microbiológicos, ressaltando que o manipulador é o
principal veículo desta transmissão, durante o preparo de
refeições (SILVA, 2001).

Sob este enfoque e buscando interfaces entre a vigilância sanitária de alimentos,a segurança alimentar,os manipuladores de alimentos e a promoção da saúde,o presente trabalho objetiva elaborar de um instrumento para atuação da Vigilância Sanitária DF na qualificação do manipulador de alimentos no Distrito Federal. 


\title{
2. REFERENCIAL TEÓRICO
}

\section{1-VIGILÂNCIA SANITÁRIA}

\begin{abstract}
É o conjunto de ações capaz de eliminar, diminuir ou prevenir riscos à saúde e de intervir nos problemas sanitários decorrentes do meio ambiente, da produção e circulação de bens e da prestação de serviços de interesse à saúde, abrangendo:

controle de bens de consumo, que direta ou indiretamente, se relacionem com a saúde, compreendidas todas as etapas e processos, da produção ao consumo.

controle da prestação de serviços que se relacionem direta ou indiretamente com a saúde. (Lei 8080/90).
\end{abstract}

A Vigilância Sanitária ganhou, a partir da publicação da Lei 8080/90, novas atribuições, com a integração das ações e serviços voltados para a saúde do trabalhador e do meio ambiente.

O objetivo de "planejar, coordenar, supervisionar, realizar estudos e propor normas e programas", abrangendo quatro subsistemas fundamentais:

- O controle de bens de consumo que direta ou indiretamente se relacionam à saúde, envolvendo todas as etapas e processos de produção até o consumo final, compreendendo portanto: matérias primas, transporte, armazenamento, distribuição, comercialização e consumo de produtos de interesse à saúde, tais como alimentos, água, bebidas, medicamentos, insumos, cosméticos, produtos de higiene pessoal, saneantes domissanitários, produtos químicos, produtos agrícolas, agrotóxicos, biocidas, drogas veterinárias, correlatos (entre eles os 
equipamentos médico-hospitalares e odontológicos), e outros.

- O controle dirigido a prestação de serviços que se relacionam direta ou indiretamente com a saúde, abrangendo entre outros, a prestação de serviços: médicohospitalares, de apoio diagnóstico, hemoterápicos, de hemodiálise, odontológicos e os que utilizam radiação; casas de repouso, de idosos, centros de convivência, creches, bancos de órgãos, de leite humano, práticas alternativas, casas de massagem, tatuagem, clínicas de emagrecimento, aplicadoras de produtos relacionados à saúde, dentre outras que podem constituir-se em risco para a população.

- O controle dirigido às ações de saneamento do meio (formas de intervenções sobre os efeitos advindos do uso e parcelamento do solo, das edificações, do sistema de produção em geral, e dos sistemas de saneamento básico coletivos e individuais), visando a promoção da saúde pública e prevenção da ocorrência de condições desfavoráveis, decorrentes das ações do Homem.

- O controle específico sobre o ambiente e processo de trabalho, estabelecendo ações, articuladas com as instâncias de representação dos trabalhadores e das outras instâncias da sociedade, para a proteção da saúde do trabalhador.

\subsubsection{PROMOÇÃO DA SAÚDE}

Em 1978 realizou-se em Alma - Ata, (União Soviética), a Conferência Internacional sobre Assistência Primária que considerou 
os cuidados primários em saúde como a "chave para o alcançar um nível de saúde aceitável em todo o mundo, num futuro próximo, como parte do desenvolvimento social e dentro do espírito da justiça social" (DHILLON, 1994). Esta Conferência teve grande repercussão entre os especialistas brasileiros em saúde pública, além da grande divulgação dos documentos oficiais do evento; fatos estes fomentadores de reflexões que culminaram na realização em 1979, do I Simpósio sobre Política Nacional de Saúde.

Patrocinado pela Comissão de Saúde da Câmara dos Deputados, o Simpósio sobre Política Nacional de Saúde, que contou com 936 participantes, representantes de todos os estados e territórios do País, aprovou "considerações doutrinárias do Centro Brasileiro de Estudos da Saúde - CEBES" ocasião em que "foram referenciados pré-requisitos para uma saúde autenticamente democrática e medidas que obstaculizam os efeitos mais nocivos da lei do mercado na área de saúde entre as quais a criação de um Sistema Único de Saúde, com a tarefa de 'planificar e executar uma política nacional de saúde que inclui a pesquisa básica, a formação de recursos humanos, a atenção médica individual e coletiva, curativa e preventiva, o controle ambiental, o saneamento e nutrição mínima à sobrevivência de uma população hígida'" (CARVALHO, 1995).

Outro evento marcante ocorreu em Ottawa, Canadá, em 1986. Foi a I Conferência Internacional sobre Promoção da Saúde, onde se definiu a promoção à saúde como a capacidade da comunidade em atuar na melhoria da sua qualidade de vida e saúde, concepção que contribuiu para modificar o papel do Estado e do indivíduo no alcance desta qualidade,

uma vez que, para atingir o nível de saúde desejado os sujeitos e os grupos deverão ser capazes de identificar seus problemas, apontar suas soluções e modificar favoravelmente, o meio ambiente (PROMOÇÃO, 1996). 
Finalmente em 1988, a Assembléia Nacional Constituinte, convocada para elaborar o novo texto constitucional brasileiro, aprova um capítulo específico sobre saúde, consumando uma conquista do Movimento Sanitário Brasileiro e instituindo as bases doutrinárias do respectivo sistema nacional. A Saúde tornou-se um serviço de relevância pública ao tempo em que foi elevada à categoria de direito social assim expresso no artigo 196 da Carta Magna:

"art. 196. A saúde é direito de todos e dever do Estado,
garantido mediante políticas sociais e econômicas que
visem à redução do risco de doença e de outros agravos e
ao acesso universal e igualitário às ações e serviços para
sua promoção, proteção e recuperação"(BRASIL, 1988).

Com a finalidade de definir parâmetros para o modelo assistencial e estabelecer os papéis das três esferas de governo, é promulgada a Lei Orgânica da Saúde (Lei n. ${ }^{\circ}$ 8.080/90) que dispõe sobre as condições para a promoção, proteção e recuperação da saúde, a organização e o funcionamento dos serviços correspondentes. Em seu artigo $6^{\circ}$ parágrafo $1^{\circ}$, define Vigilância Sanitária como sendo um conjunto de ações capazes de eliminar, diminuir ou prevenir riscos à saúde e de intervir nos problemas sanitários decorrentes do meio ambiente, da produção e circulação de bens e da prestação de serviços de interesse da saúde (BRASIL, 1990).

Em 1989, um grupo interessado em promoção da saúde nos países em desenvolvimento reuniu-se em Genebra, Suíça, e produziu um documento estratégico "A call for action" (um chamado para a ação), o qual pretendia estender a promoção da saúde aos países em desenvolvimento, buscando encorajar as pessoas a fazerem escolhas saudáveis e capacitando-as para viverem de maneira mais saudável. 
A conferência seguinte foi a de Sundsvall, Suécia, em 1991, que trato dos ambientes favoráveis à saúde. A seguir, em 1992, em Bogotá, Colômbia, uma conferência especialmente voltada para a promoção da saúde na América Latina, teve como escopo os desafios da solidariedade e da eqüidade social.

Em 1997, a Conferência de Jacarta, na Indonésia, pela primeira vez, incluiu o setor privado nas discussões sobre a promoção da saúde. Esta conferência preocupou-se, também, com as tendências demográficas; com as doenças infecciosas reemergentes e com os fatores transnacionais, como a globalização e a degradação ambiental.

Em 1988, novamente em Genebra foi criada a rede de Megapaíses para a Promoção da Saúde, reunindo os países mais populosos no mundo, que representavam $60 \%$ da população mundial. Entre os onze países, com mais de 100 milhões de habitantes, que a compõem, inclui-se o Brasil. Sua missão consiste em fortalecer a capacidade de promoção da saúde às populações dos megapaíses e à promoção mundial.

A conferência de Promoção da Saúde, realizada no ano 2000, na Cidade do México, reafirmou a importância da promoção da saúde no âmbito local, regional, nacional e internacional, reforçou a necessidade de ações conjuntas de todos os setores da sociedade, salientou a relevância de fortalecer as redes nacionais e internacionais de promoção da saúde, e defendeu a idéia de que os órgãos da Organização das Nações Unidas (ONU) sejam responsáveis pelo impacto em termos de saúde de sua agenda de desenvolvimento.

Em novembro de 2000, realizou-se em São Paulo, Brasil, a III Conferência Regional Latino-Americana com a proposta de promover uma visão crítica da promoção da saúde e educação para a saúde. Como resultado do evento, os países participantes consignaram a 
Carta de São Paulo pela promoção da Saúde, na qual se preconizava a favor da eqüidade, da participação social e pela melhoria das condições de saúde e qualidade de vida.

Em termos práticos, várias são as definições propostas para Promoção da Saúde. Alguns a vêem como ação social, educacional e política que amplia a consciência sobre saúde da população, encorajando estilos de vida saudáveis e ações comunitárias que apóiem a saúde.

Segundo BUSS (2000), promoção da saúde é o conjunto de atividades, processos e recursos, de ordem institucional, governamental ou da cidadania, orientados a propiciar a melhoria nas condições de bem-estar e acesso a bens e serviços sociais, que favoreçam o desenvolvimento de conhecimentos, atitudes e comportamentos favoráveis ao cuidado da saúde e desenvolvimentos de estratégias que permitam à população maior controle sobre sua saúde e suas condições de vida, nos níveis individual e coletivo.

Promoção da Saúde na área de alimentos deve ser entendido como o conjunto de ações dos setores público e privado, de indivíduo e grupos, que tenham por finalidade garantir a segurança dos alimentos. Portanto, constitui papel do Estado emitir leis, fiscalizar e educar. Cabe às organizações privadas instituir programas e implantar sistemas que atendam à legislação e propiciem a melhoria da qualidade, com ênfase nas atividades de capacitação de recursos humanos(GERMANO, 2003).

O direito constitucional a saúde tem sido buscado por todos. Em que se pese a falta de capacidade do governo e a falta de conhecimentos do consumidor, é inevitável que temos avançado na busca da produção e do serviço de alimentos que tragam segurança para quem os consomem e para quem os produzem. Neste cenário de conhecimento técnico e de tecnologias inovadoras de produção, um 
fator continua sendo o grande desafio da ciência dos alimentos: a correta manipulação (SANTOS, 1999).

A direção do estabelecimento deve tomar providências para que todas as pessoas que manipulem alimentos recebam instrução adequada e contínua em matéria higiênico-sanitária, na manipulação dos alimentos e higiene pessoal, com vistas a adotar as precauções necessárias para evitar a contaminação dos alimentos (BRASIL, 1997).

A prevenção é melhor que a cura. Sempre é melhor prevenir a possibilidade de intoxicação alimentar, o apodrecimento ou a contaminação, do que ter que curar as eventuais epidemias. A melhor maneira de prevenir é garantindo que todos os empregados tenham uma boa educação e sejam ensinados sobre os requisitos básicos das boas práticas de higiene antes de terem permissão para começar o seu trabalho (HAZELWOOD, 1994).

A prevenção das toxinfecções alimentares deve ser levada em consideração, antes mesmo do início da implantação operacional para a realização dos cardápios. No recrutamento de Recursos Humanos contratando funcionários especializados ou treinados para as diversas funções; no Departamento de Treinamento (Gerência de Treinamento), contratando funcionários especializados para desenvolver atividades específicas de Treinamento e controle de Qualidade, atuando no Homem, Ambiente, Alimentos e Supervisão Técnica (SILVA, 1995).

\subsection{LEGISLAÇÃO BRASILEIRA}

Historicamente, desde os povos mais remotos de que se tem conhecimento, os cuidados com alimentos, visando garantir sua integridade para o consumo humano, parecem estar relacionados a preceitos religiosos e/ou culturais. Há vários séculos, os governantes passaram, igualmente, a cuidar da qualidade higiênico sanitária dos 
produtos alimentícios, emitindo sanções para aqueles que os comercializavam adulterados ou deteriorados que não atendiam, portanto, às especificações previstas.

A manutenção da saúde depende de uma boa alimentação através do equilíbrio nutricional. A dieta desequilibrada propicia uma deficiência orgânica aumentando a nossa susceptibilidade às doenças, potencializando a ação dos microrganismos patogênicos. Portanto a relação saúde e doença é diretamente proporcional ao equilíbrio da dieta e ao controle higiênico-sanitário dos alimentos.

O Decreto Lei no 986(BRASIL,1969), fixou um critério de qualidade do alimento para cada tipo ou espécie, ampliando o conceito de Padrão de Identidade e Qualidade do Alimento (PIQ). Estabeleceu, também princípios de higiene a serem observados na obtenção, manipulação, armazenamento, transporte e distribuição de alimentos, abrangendo o cultivo e a produção. Ademais, recomendou normas de higiene para manipuladores de alimentos.

Visando melhorar as condições higiênico-sanitárias na preparação de alimentos e adequar a ação da Vigilância Sanitária, o Ministério da Saúde publicou a Portaria 1428(BRASIL, 1993), recomendando que seja elaborado um "manual de boas práticas de manipulação de alimentos", baseado nas publicações técnicas da SBCTA,OMS e Codex Alimentarius.

Boas Práticas de Fabricação, segundo a Portaria n¹428(BRASIL, 1993), são normas de procedimentos para atingir um determinado padrão de identidade e qualidade de um produto e/ou de um serviço na área alimentos, cuja eficácia e efetividade deve ser avaliada através da inspeção e/ou da investigação. Aqui incluem-se também produtos tais como: bebidas, aditivos, embalagens, utensílios e materiais em contato com alimentos. 
Posteriormente, em agosto de 97 foi publicada a Portaria Ministerial No326 (BRASIL, 1997), definindo as condições técnicas para a elaboração do manual de boas práticas, procurando abranger todos os aspectos que envolvem a elaboração/industrialização de alimentos, desde a origem até a distribuição, referindo-se a importância dos aspectos ligados à manipulação e aos manipuladores e incluem a temática da higiene pessoal, bem como os requisitos sanitários na elaboração dos produtos.

Todas estas publicações oficiais visam um melhor entrosamento entre o que se vai produzir com o que se vai fiscalizar, tendo como conseqüência um alimento com melhor qualidade higiênico-sanitária.

Para isso fica obrigatória a presença de um profissional que se responsabilize:

- Pela elaboração do manual de boas práticas de fabricação;

- Pela aplicação das técnicas de controle descritas no manual;

- Pela elaboração do fluxograma de produção compatível com a planta do estabelecimento.

Neste sentido, o manual de boas práticas de manipulação deve descrever a situação real dos procedimentos técnicos para cada estabelecimento em especial, constituindo o programa de prérequisitos básicos para implantação do Sistema de Análise de Perigos e Pontos Críticos de Controle (APPCC); compreende:
a) Controle de saúde dos funcionários,
b) Controle da água para consumo,
c) Controle integrado de pragas, 
d) Regras para visitantes,

e) Controle de matérias-primas,

f) Adequação estrutural do estabelecimento,

g) Higiene pessoal, ambiental e de alimentos,

h) Manipulação e processamento dos alimentos nas etapas básicas de preparação (recebimento, armazenamento, pré-preparo/ preparação, cocção, refrigeração, congelamento, descongelamento, reaquecimento, porcionamento, distribuição e transporte).

Conjuntamente com as boas práticas de fabricação, a Agência Nacional de Vigilância Sanitária (ANVISA), através da Resolução da Diretoria Colegiada (RDC) $n^{\circ} 275$ (BRASIL,2002) definiu o Regulamento Técnico de Procedimentos Operacionais Padronizados (POPs), com a finalidade de contribuir para a garantia das condições higiênico-sanitárias, aplicados aos estabelecimentos produtores e industrializadores de alimentos; compreende :

a) Higienização das instalações, equipamentos, móveis e utensílios;

b) Controle da potabilidade da água;

c) Higiene e saúde dos trabalhadores;

d) Manejo de resíduos;

e) Manutenção preventiva e calibração de equipamentos;

f) Controle integrado de vetores e pragas urbanas;

g) Seleção das matérias-primas, ingredientes e embalagens;

h) Programa de recolhimento de alimentos. 
Os POPs devem ser aprovados, datados e assinados pelo responsável técnico, responsável pela operação, responsável legal e/ ou proprietário do estabelecimento, firmando o compromisso de implementação, monitoramento, avaliação, registro e manutenção dos mesmos. Os funcionários devem estar devidamente capacitados para a execução dos POPs.

A aplicação das Boas Práticas de Fabricação - BPF e do sistema de Análise de Perigos e Pontos Críticos de Controle por parte de governos, indústrias e consumidores, podem identificar os perigos concretos (biológicos, físicos e químicos) e adotar as devidas medidas preventivas.

O sistema de Análise de Perigos e Pontos Críticos de Controle (APPCC) foi desenvolvido para garantir a produção de alimentos seguros à saúde do consumidor. Seus princípios são utilizados no processo de melhoria da qualidade, contribuindo para a maior satisfação do consumidor, tornando as empresas mais competitivas e ampliando as possibilidades de conquista de novos mercados, principalmente o externo.

O Sistema é recomendado por organismos internacionais com a Organização Mundial do Comércio (OMC), a Organização das Nações Unidas para Alimentação e Agricultura (FAO) e a Organização Mundial de Saúde (OMS) e já é exigido por alguns segmentos do setor alimentício da Comunidade Econômica Européia (CEE) e dos Estados Unidos (EUA). No Mercosul já está sendo estudada sua exigência como ferramenta de equivalência.

Para implantação do sistema APPCC é necessário que seja elaborado o plano APPCC, que é constituído pelas seguintes etapas:

- Formação da equipe APPCC: uma equipe de profissionais que se responsabilizem pelo desenvolvimento e implantação do sistema. 
- Descrição dos produtos e ingredientes.

- Uso intencional dos produtos.

- Construção do diagrama de fluxo (fluxograma).

- Verificação do fluxograma in loco.

- Principio 1: Análise de Perigos e Medidas de Controle

- Principio 2: Determinação dos Pontos Críticos de Controle

- Principio 3: Definição dos Limites Críticos (critérios)

- Principio 4: Realização da monitorização

- Principio 5: Ações Corretivas

- Principio 6: Procedimentos de Verificação

- Principio 7: Procedimentos de Registro

Esta tecnologia de aplicação recente busca oferecer aos consumidores alimentos inócuos, que não representam risco a sua saúde. É importante ressaltar que as Boas Práticas de Fabricação e os POPs englobam o controle higiênico das operações e são prérequisitos para o sistema APPCC que define os controles críticos com ênfase ao controle sanitário dos alimentos.

A exemplo de outros segmentos, a gestão da qualidade na indústria de alimentos modificou-se a partir dos anos 80 , assumindo feição pró-ativa. Assim, ao sistema denominado Boas Práticas de Fabricação (BPF), que se complementava por programas de análises laboratoriais dos lotes produzidos, visando garantir a qualidade,somou-se o de Análise de Perigos e Pontos Críticos de Controle (APPCC), versão brasileira do internacionalmente conhecido Hazard Analysis and Critical Control Point, constituindo-se dessa forma a moderna base da gestão da qualidade na indústria de 
alimentos, conforme vem sendo adotada em todo o mundo (GUIA, 2000).

Entre outras, o Sistema APPCC apresenta as vantagens de ser preventivo mediante enfoque dinâmico na cadeia de produção; de garantir a segurança e qualidade alimentar; de incrementar a produtividade e a competitividade; atender às exigências dos mercados internacionais e à legislação brasileira.

\subsection{SEGURANÇA ALIMENTAR}

O conceito de segurança alimentar foi originalmente utilizado na Europa a partir da I Grande Guerra. Sua origem estava profundamente ligada ao conceito de segurança nacional e à capacidade de cada país produzir sua própria alimentação de forma a não ficar vulnerável a possíveis cercos, embargos ou boicotes de motivação política ou militar.

As primeiras referências ao conceito em âmbito internacional se reportam, segundo Lehman, à década de 40, em suas próprias palavras:

\footnotetext{
Em 1943, os 44 governos aliados reuniram-se em Hot Springs, Virginia, e colocaram o conceito de segurança alimentar como um direito humano no centro do debate sobre Segurança Alimentar. Dois anos mais tarde, 44 representantes dos governos reunidos em Bretton Woods, $\mathrm{Ne}$ Hampshire, articularam o referencial teórico para uma nova ordem mundial baseada no Livre Comércio (VALENTE,1999).
}

A primeira referência internacional ao conceito, no âmbito da FAO, vem relacionada à discussão da Assistência Alimentar na VII Sessão da Conferência da FAO em novembro de 1953, onde a assistência alimentar, utilizando os excedentes de alimentos era vista como um componente de segurança alimentar. 
No entanto, o conceito de Segurança Alimentar irrompe com força no cenário mundial a partir da crise de escassez de 1972-74 e dos acordos estabelecidos na Conferência Mundial de Alimentação de 1974. Nesta Conferência foi proposto que todos os países do mundo criassem estoques de alimentos que poderiam ser utilizados em situações de emergência como a ocorrida no início da década de 70. Naquela época, a segurança Alimentar se afastava do pano de fundo dos direitos humanos e, dentro de uma visão essencialmente produtivista e neo-malthusiana se conceituava como: "... uma oferta de alimentos segura e adequada com base em critérios de necessidade fisicamente estabelecidos."

Isto implicava que a segurança alimentar fosse conceituada como uma política de armazenamento estratégico e de oferta segura e adequada de alimentos, e não como um direito de todo ser humano de ter acesso a uma alimentação saudável. O enfoque estava na comida e não no ser humano.

O final da década de 70 caracterizou-se por um clima de certo otimismo. Aumentou a produção de alimentos no mundo e caíram os preços mundiais de alimentos, até mesmo abaixo dos níveis da década de 50. Neste novo contexto perderam força os argumentos neo malthusianos de que o mundo não teria condições de aumentar a produção de alimentos em ritmo igual ou maior que o aumento da população, e de que esta seria a causa principal dos problemas alimentares. Reforça-se o entendimento que os problemas da fome e da desnutrição eram decorrentes muito mais de problemas de demanda e distribuição, ou seja de acesso, do que de produção.

Em 1983, a FAO definiu um novo conceito de Segurança Alimentar que se baseava em três objetivos: oferta adequada de alimentos; estabilidade da oferta e dos mercados de alimentos; segurança no acesso aos alimentos ofertados. Este conceito foi aprovado pelo Comitê de Segurança Alimentar Mundial, pelo 
Conselho da FAO, pelo Conselho Mundial de Alimentação e pelo Conselho de Assuntos Econômicos e Sociais.

Em 1986, com base nestes avanços de entendimento, o Banco Mundial define Segurança Alimentar como "... o acesso por parte de todos, todo o tempo, a quantidades suficientes de alimentos para levar uma vida ativa e saudável" (VALENTE, 1999).

Com base neste conceito passou-se a considerar prioritariamente os seguintes aspectos na abordagem à segurança alimentar: a insegurança alimentar é essencialmente uma falta de poder aquisitivo; a segurança alimentar não pode ser vista como uma decorrência da auto-suficiência em termos alimentares; a segurança alimentar a curto prazo requer a redistribuição do poder aquisitivo e dos recurso materiais; a segurança alimentar a longo prazo requer crescimento e redução da pobreza.

No final da década de 80 e início da de 90 observa-se mais uma modificação no conceito de segurança alimentar. Incorpora-se ao mesmo as noções de alimento seguro (não contaminado biológica ou quimicamente); de qualidade do alimento (nutricional, biológica, sanitária e tecnológica); do balanceamento da dieta, da informação e das opções culturais (hábitos alimentares) dos seres humanos em questão.

Ao mesmo tempo, considera-se a questão da eqüidade e da justiça, especialmente no que tange a questão das relações éticas entre a geração atual e as futuras gerações, o uso adequado e sustentável dos recursos naturais, do meio ambiente e do tipo de desenvolvimento adotado. Considera-se a discussão dos modos-devida sustentáveis. A questão do direito à alimentação passa a se inserir no contexto do direito à vida, da dignidade, da autodeterminação e da satisfação de outras necessidades básicas. 
A Conferência Internacional de Nutrição, promovida conjuntamente pela FAO e pela OMS consolida esta conceituação nos compromissos assumidos, humanizando o conceito de segurança alimentar. Fortalece-se o conceito de segurança alimentar domiciliar, em que além do componente de segurança alimentar entendido como oferta e acesso à alimentação de qualidade, incorpora-se a assistência básica à saúde (abastecimento de água, saneamento, saúde pública) e o cuidado provido no lar aos membros da família (carinho, atenção, preparo do alimento, aleitamento materno, estimulação psicossocial, informação, apoio educacional, etc).

Mais recentemente, observa-se um forte movimento em defesa da Segurança Alimentar como questão de direito humano básico, expressa em movimentos nacionais e internacionais relacionando a questão da alimentação e da nutrição à cidadania. Este direito deve ser garantido por políticas públicas, sendo público ora entendido por uma esfera que incorpora agentes públicos e privados.

O papel do Estado é o proteger estes direitos (durante quebras de produção, calamidades naturais, desemprego, quedas de salários reais, piora das relações de troca, etc) e de promoção dos mesmos direitos (promover o aumento do poder da população sobre sua própria vida, promoção da cidadania, da educação, da participação, da autonomia, etc).

A participação ativa e parceira da sociedade civil deve ocorrer através de suas organizações próprias neste esforço público, especialmente nas áreas onde o estado é incapaz de agir, por sua falta de flexibilidade e capilaridade; deve romper com a tendência maniqueísta de opor o mercado e o estado. O importante é entender que cada setor tem o seu papel e cabe à sociedade civil mediar a 
ação das diferentes instituições e os papéis que podem ser mutuamente complementares e sinérgicos em muitos casos.

O acesso à alimentação é um direito humano prioritário, acima de qualquer outra razão que possa justificar sua negação, seja de ordem econômica ou política.

Assim, o conceito moderno, adotado no Brasil a partir da I Conferência Nacional de Segurança Alimentar (I CNSA, 1994), ressalta a importância do componente nutricional da segurança alimentar e apresentam qualidade e quantidade adequadas à promoção e à conservação da saúde.

Geralmente a Segurança Alimentar é associada exclusivamente ao combate à fome. Apesar da fome consistir em um dos principais problemas de insegurança alimentar no Brasil, existem outros problemas que também exigem ações concretas nesta área. Entre estes podem ser citadas: as doenças causadas por diferentes tipos de contaminação ou da própria qualidade do alimento (diarréias, contaminação por agrotóxicos, presença de hormônios, composição inadequada, etc); as doenças associadas a hábitos alimentares inadequados, tais como obesidade, sobrepeso, diabetes, hipertensão, doenças cardíacas, doenças vasculares e cânceres.

Grande parte das crianças que ficam desnutridas ou morrem de desnutrição são vítimas de infecções intestinais causadas por alimentos contaminados ou inadequados para o consumo, $e$ atualmente, são a maior causa de morte precoce dos brasileiros, especialmente dos mais pobres que não têm acesso a medidas de saúde preventiva ou curativa.

Mesmo entendendo que a Segurança Alimentar depende de políticas e ações em nível nacional e estadual, é no nível do município e no próprio domicílio que a Segurança Alimentar se 
concretiza ou não, uma vez que muito pode ser realizado ou por ação governamental articulada, ou por ações de parceria entre a sociedade civil e o governo, ou por ações cidadãs de solidariedade e auto-ajuda.

Os três grandes eixos de diretrizes para uma Política de Segurança Alimentar foram traçados pelo Conselho Nacional de Segurança Alimentar(CONSEA), e foram deliberadas da I CNSA:

I. Ampliar as condições de acesso à alimentação e reduzir o seu peso no orçamento familiar. Neste eixo estão incluídas as ações públicas que têm por objetivo garantir:

- o acesso à terra e condições para nela produzir;

- consolidação e apoio à agricultura familiar;

- o estímulo à produção de alimentos básicos;

- estímulo a criação de fortalecimento de pequenas empresas urbanas e rurais;

- estímulo ao associativismo e ao cooperativismo;

- a capacitação profissional, gerencial e administrativa de trabalhadores e micro empresários;

- iniciativas de Garantia da Renda Mínima (Campinas renda mínima; Brasília - Bolsa Escola, etc)

- o abastecimento alimentar a preços justos para áreas de baixa renda, articulando o produtor com o consumidor.

II. Assegurar saúde, nutrição e alimentação a grupos populacionais determinados. Neste eixo estão incluídas as ações que visam garantir alimentação regular para grupos 
populacionais com maior risco de desenvolverem doenças decorrentes de uma alimentação inadequada:

- Descentralização do Programa de recuperação de crianças e gestantes desnutridas (INAN/MS);

- Programa Nacional de Alimentação Escolar (FAE/MEC);

- Programa Nacional de Distribuição de Alimentos (CONAB/MAARA)

- Outros programas dirigidos a trabalhadores, desempregados, idosos, enfermos e pessoas institucionalizadas.

III. Assegurar a qualidade biológica, sanitária, nutricional e tecnológica dos alimentos e seu aproveitamento, estimulando práticas alimentares e estilos de vida saudáveis:

- Vigilância e controle de qualidade dos alimentos em todos os pontos da cadeia alimentar, desde a roça até os locais de consumo (domicílio, restaurantes, bares, ambulantes, etc), passando pelos locais de produção e comercialização;

- Direito de acesso à informação sobre a composição dos alimentos, prazos de validade, etc.

- Fornecimento regular de informações sobre hábitos alimentares e estilos de vida saudáveis;

- Criação de oportunidades de acesso a programas supervisionados de atividades físicas a todos os cidadãos. 
Os alimentos são afetados pelo uso abusivo de substâncias químicas agrícolas e aditivos não autorizados, por contaminação ambiental e práticas inadequadas de manipulação de alimentos. A possibilidade de controlar esses perigos ou de mantê-los dentro de níveis aceitáveis para o consumidor depende, em grande parte, da capacidade dos produtores e das autoridades encarregadas de controlar os alimentos para regular, prevenir ou reduzir ao mínimo a ocorrência de tais perigos (OPAS, 2001).

A preocupação com o controle de qualidade torna-se ainda mais relevante quando se analisa o desenvolvimento da indústria alimentícia no Brasil. Por exemplo, observando-se o setor de refeições coletivas no país, verifica-se um crescimento de $20 \%$ ao ano. Dados recentes estimam que aproximadamente 17 milhões de refeições diárias são produzidas por restaurantes instalados em fábricas, escolas, hospitais, buffets e centros empresariais, representando um atendimento de cerca de $28 \%$ da população ativa (MACÊDO, 1996).

Qualidade e segurança são componentes, hoje, indispensáveis para produções alimentares $e$ as indústrias reconhecem os benefícios advindos da necessidade de se trabalhar corretamente os alimentos, garantindo suas propriedades nutricionais, tecnológicas e sanitárias. Num mercado altamente competitivo, muitos países querem vender alimentos e os que compram são suficientemente inteligentes para exigir qualidade, segurança e preço justo. Em tal contexto, o Brasil vive uma realidade no mínimo paradoxal: possui empresas de alimentos que, sem nenhum favor, poderiam estar no primeiro mundo e, ao mesmo tempo, enfrentam problemas primários, geralmente na esfera sanitária (PANETTA, 2001).

A segurança alimentar é preocupação de todos os profissionais de saúde pública, particularmente daqueles da Vigilância Sanitária de Alimentos. As doenças transmitidas pelos 
alimentos representam considerável grau de morbidade e mortalidade na população,advindos especialmente da contaminação de origem microbiana, decorrente da manipulação inadequada.

O manipulador é considerado fundamental para o controle e sempre que não houver tratamento térmico adequado. O treinamento destes funcionários é elemento chave para garantir alimentos com adequado padrão higiênico sanitário. Implantar ações educativas é uma necessidade para suprir a falta de conhecimentos, sobretudo devido ao baixo grau de escolaridade destas pessoas. Cabe aos profissionais dos serviços de inspeção buscar um maior envolvimento no treinamento dos funcionários dos estabelecimentos sob sua responsabilidade (GERMANO, 2001).

\subsection{MANIPULADOR DE ALIMENTOS}

Segundo a OMS, o termo "manipuladores de alimentos", em seu sentido mais amplo, corresponde a todas as pessoas que podem entrar em contato com um produto comestível em qualquer etapa da cadeia alimentar desde a sua fonte até o consumidor (GERMANO, 2001).

As pessoas que colhem, manipulam, armazenam, transportam, processam ou preparam alimentos são muitas vezes responsáveis por sua contaminação. Todo manipulador pode transferir patógenos a qualquer tipo de alimento, mas isso pode ser evitado através de higiene pessoal, comportamento e manipulação adequados. Os indivíduos envolvidos no processamento de alimentos devem ser treinados e conscientizados sobre a importância das Boas Práticas de Fabricação (OPAS, 2001).

Todos os alimentos, da produção até o consumo, necessitam de uma avaliação completa dos possíveis perigos que poderão 
causar à saúde. Atualmente o controle da qualidade vem sendo baseado no sistema de análise de perigo e pontos e críticos de controle (APPCC/HACCP). Este sistema é principal meio que a indústria alimentícia e estabelecimentos responsáveis pela manipulação de alimentos possuem para assegurar a inocuidade e segurança de seus produtos.

O sucesso desse sistema depende, no entanto, dos programas de Boas Práticas de Fabricação (BPF/GMP), que controlam o ambiente onde ocorre a manipulação dos alimentos. Os manipuladores devem adquirir conhecimento sobre a fundamental importância na higiene e sanidade dos produtos, visto que cabe a eles grande parte do manuseio, tornando-se assim fonte potencial de contaminação, caso ocorram falhas no processo de preparo. Paralelamente, verifica-se que com todo conhecimento sobre higiene dos alimentos e sua influência na prevenção das enfermidades de origem alimentar, surtos e casos esporádicos continuam a acontecer.

A maioria dos surtos e toxinfecções reportados relacionados às toxinfecções alimentares acontecem em cozinhas industriais devido à ausência de controle dos possíveis veiculadores, e principalmente, da manipulação dos alimentos favorecendo o desenvolvimento de microrganismos causadores desses surtos como Bacillus cereus e a Salmonella. Os manipuladores devem ser treinados para ter claro entendimento dos procedimentos de preparação e da manipulação dos alimentos que irão produzir (MAGALHÃES, 2001).

O conteúdo programático dos treinamentos deve conter informações sobre : as principais causas de acidentes em cozinhas; a prevenção de incêndio; o uso de equipamentos de proteção individual (E.P.I.); os equipamentos obrigatórios na cozinha; a postura profissional; a higiene e a aparência pessoal, os cuidados com o lixo e panos de pratos; as instalações sanitárias; noções de 
microbiologia; importância das relações tempo-temperatura na conservação dos alimentos e prevenção às toxinfecções alimentares (MAGALHÃES, 2001).

Os manipuladores de alimentos exercem papel significativo na transmissão de toxinfecções alimentares causadas por Staphilococus aureus, freqüentemente encontrado nas lesões sépticas das mãos. Desta maneira, estas devem ser higienizadas com freqüência e sempre que houver troca de tarefas. O uso de luvas descartáveis é indicado somente para atividades de finalização de preparações. Segundo o Laboratório Central do Instituto Adolfo Lutz, o S. aureus esteve envolvido em $40 \%$ dos surtos ocorridos no período de 1994-1998 (QUEIROZ,2000).

A Organização Mundial de Saúde define doença transmitida por alimento como "uma doença de natureza infecciosa ou tóxica causada por, ou através do, consumo de alimento ou água contaminados".

Os alimentos destinados ao consumo humano estão expostos a um meio contaminado, podendo ter contaminações na origem ou em seu processamento por meio de manipuladores ou dos processos de manipulação.

O trato intestinal do homem e dos animais, rico em microrganismos, em quantidade e variedade, é uma das principais fontes de agentes patogênicos. Em condições muito precárias de higiene, os microrganismos do trato gastrointestinal podem contaminar as mãos dos manipuladores e, conseqüentemente, os alimentos por eles preparados.

A higienização inadequada de equipamentos e utensílios constitui outro fator relevante de risco, favorecendo a contaminação cruzada cuja fonte pode ser a matéria-prima (animal ou vegetal), o ar, o pó e o próprio manipulador. 
Devido à importância que a contaminação de alimentos representa para a saúde pública e ao fato de que, mais freqüentemente, são apontadas como causas predisponentes para tais contaminações a manipulação incorreta dos alimentos, este trabalho pretende discutir argumentos favoráveis e desfavoráveis à regularização desta ocupação.

Calcula-se que de 1 milhão a 100 milhões de indivíduos no mundo, contraem toxinfecções decorrentes do consumo de alimentos e de água, anualmente. Dentre as doenças transmitidas por alimentos tem-se as de origem física, química e microbiológica.

Para fins da discussão a que objetiva este trabalho, serão levadas em consideração as de origem microbiológica, uma vez que todos os alimentos já se apresentam naturalmente contaminados pelos mais diversos tipos de microrganismos. Portanto, a grande preocupação é impedir que os microrganismos sobrevivam, se multipliquem e que outros tipos sejam acrescentados às matériasprimas, como conseqüência de contaminação ambiental ou por manipulação inadequada.

As enfermidades veiculadas por alimentos estão diretamente relacionadas aos microrganismos patogênicos que podem ser classificadas como: clássicos, emergentes e reemergentes.

A maioria das pessoas envolvidas com a manipulação de alimentos, nos estabelecimentos alimentícios, carece de conhecimentos relativos aos cuidados higienicos-sanitários, que devem ser seguidos na cadeia de produção, desconhecendo totalmente a possibilidade de serem portadores assintomáticos de microrganismos. Como conseqüência, tem-se prática inadequada de higiene e de processamento realizadas por pessoas inabilitadas.

Atualmente, no Distrito Federal, não há nenhuma legislação que regulamente a ocupação de manipulador de alimentos; em nível 
nacional, há os regulamentos técnicos que estabelecem parâmetros e critérios para o controle higienico-sanitário na produção de alimentos.

A higiene alimentar é parte do processo de ensino de todos os manipuladores de alimentos, mas até agora, não tem sido avaliada através de exames reconhecidos em âmbito nacional e não existe definição de um conteúdo programático mínimo na preparação destes profissionais. É importante salientar que saúde e alimentos estão estritamente relacionados.

Os avanços tecnológicos na produção e o aumento do consumo resultaram na mudança dos padrões sanitários de toda cadeia, com vistas a evitar ou diminuir os riscos de toxinfecções alimentares, através da qualidade e da segurança alimentar (GERMANO, 2000).

Os manipuladores de alimentos são predominantemente, do sexo masculino na grande maioria das funções e das empresas. Existe claro antagonismo entre funcionários antigos e treinadores com menor experiência/idade na cozinha. Talvez esta condição interfira mesmo na percepção dos manipuladores a respeito de serem passíveis de causar risco aos consumidores ao não seguir os procedimentos higiênico-sanitários adequados; ou talvez eles não se sintam predispostos a assumir que desconhecem os procedimentos adequados e tenham dificuldade para admitir sua ignorância e pedir ajuda a pessoas do sexo oposto.

No que concerne aos dados referentes à faixa etária dos manipuladores, verifica-se maior concentração nas idades entre 18 e 40 anos, o que parece lógico, pois constitui o grupo populacional dos jovens e jovens adultos com toda força e disposição para trabalhar (GERMANO, 2003). 


\section{OBJETIVOS}

\subsection{OBJETIVO GERAL}

Elaborar instrumento ou proposta para atuação da Vigilância Sanitária na qualificação do manipulador de alimentos do Distrito Federal.

\subsection{OBJETIVOS ESPECÍFICOS}

- Analisar a legislação brasileira diretamente relacionada ao manipulador de alimentos.

- Propor um programa de educação sanitária para manipuladores de alimentos no Distrito Federal ;

- Verificar as recomendações legais sobre manipulador de alimentos;

- Verificar aspectos relacionados ao manipulador citados em Boas Práticas de Fabricação e o método Análise dos Perigos e Pontos Críticos de Controle. 


\section{JUSTIFICATIVA}

As pessoas que colhem, manipulam, armazenam, transportam, processam ou preparam alimentos são muitas vezes responsáveis por sua contaminação.Todo manipulador pode transferir patógenos a qualquer tipo de alimento, mas isso pode ser evitado através de higiene pessoal, comportamento e manipulação adequados.Os indivíduos envolvidos no processamento de alimentos devem ser treinados e conscientizados sobre a importância das Boas Práticas de Fabricação (OPAS, 2001).

Sempre é melhor prevenir a possibilidade de intoxicação alimentar.A melhor maneira de prevenir é garantindo que todos os empregados tenham uma boa educação e sejam ensinados sobre os requisitos básicos das boas práticas de higiene antes de terem permissão para começar o seu trabalho (HAZELWOOD, 1994).

O treinamento destes funcionários é elemento chave para garantir alimentos com adequado padrão higiênico sanitário. Existe necessidade de implantar ações educativas para suprir a falta de conhecimentos, sobretudo devido ao baixo grau de escolaridade destas pessoas. Cabe aos profissionais dos serviços de inspeção buscar um maior envolvimento no treinamento dos funcionários dos estabelecimentos sob sua responsabilidade.

Atualmente, no Distrito Federal, não há legislação que regulamente a ocupação de manipulador de alimentos; em nível nacional, há regulamentos técnicos que estabelecem os parâmetros e critérios para o controle higiênico sanitário na produção de alimentos.

A necessidade de implantar e implementar um instrumento legal, que exija a obrigatoriedade de treinamentos para manipuladores em estabelecimentos comerciais de alimentos. 


\section{MÉTODO}

Trata-se de pesquisa bibliográfica sobre manipulador de alimentos, visando a qualidade e segurança alimentar, onde foram enfocadas a responsabilidade e participação dos segmentos: governo, regulado e consumidores. A pesquisa foi direcionada em artigos, trabalhos publicados, legislação sanitária e internet. Organizados por tópicos referentes a: Vigilância Sanitária Promoção da saúde; legislação brasileira, Segurança Alimentar e manipuladores de alimentos. 


\section{CONCLUSÃO}

Das pesquisas realizadas conclui-se sobre a necessidade de:

- Elaborar instrumento legal para atuação da Vigilância Sanitária na qualificação do manipulador de alimentos do Distrito Federal;

- Analisar a legislação brasileira diretamente relacionada ao manipulador de alimentos;

- Verificar as recomendações legais sobre manipulador de alimentos;

- Verificar aspectos relacionados ao manipulador citados em Boas Práticas de Fabricação (BPF) e o método Análise dos Perigos e Pontos Críticos de Controle (APPCC) no contexto de Segurança Alimentar;

- Propor um programa de Educação Sanitária para manipuladores de alimentos no Distrito Federal.

Considerando que o treinamento destes funcionários é elemento chave para garantir alimentos com adequado padrão higiênico sanitário. Implantar ações educativas supriria a falta de conhecimentos, sobretudo devido ao baixo grau de escolaridade destas pessoas. 


\section{RECOMENDAÇÕES}

Atualmente, no Distrito Federal, não há legislação que regulamente a ocupação de manipulador de alimentos; em nível nacional, há regulamentos técnicos que estabelecem parâmetros e critérios para o controle higiênico sanitário na produção de alimentos. Baseado nas pesquisas bibliográficas realizadas neste trabalho, sugere-se à Diretoria de Vigilância Sanitária o projeto de lei visando a qualificação dos Manipuladores de Alimentos no Distrito Federal.

\subsection{MINUTA DE PROJETO MANIPULADOR DE ALIMENTOS DF}

Secretaria de estado de Saúde

Portaria $n^{\circ} \quad$ de 09 de abril de 2004

Dispõe sobre exigência de Treinamento para o Exercício de Ocupação ou Atividade na Área de Alimentos no âmbito do Distrito Federal.

O Secretário de Saúde, no uso de suas atribuições legais, objetivando o estabelecimento de critérios que permitam o alcance da qualidade na produção, elaboração, manipulação, comercialização e prestação de serviços na área de alimentos, de forma a assegurar a segurança alimentar e a proteção da saúde do usuário/consumidor, e ainda:

A Lei Federal nº 8080/90,

A Portaria no 1428 de 26/11/1993,

A Portaria SVS/MS n 326 , de 30 de julho de 1997, 
A RDC n² 275 de 21/10/2002;

RESOLVE:

Art.10 - Ficam as pessoas físicas ou jurídicas que possuam pelo menos 01(um) estabelecimento, sediado no Distrito Federal, no qual sejam realizadas umas das seguintes ocupações/ atividades: produção/ industrialização, fracionamento, armazenamento, comercialização e/ou transporte de alimentos, a cumprir integralmente as disposições do Anexo I da Portaria SVS/MS n 326 , de 30 de julho de 1997, que institui o "Regulamento Técnico sobre as Condições Higiênico-Sanitárias e de Boas Práticas de Fabricação e Prestação de Serviços para Estabelecimentos da área de Alimentos".

Art. $2^{\circ}$ - Para fins de cumprimento do artigo anterior, a direção do(s) estabelecimento(s) deve(m) tomar providências para que todas as pessoas que manipule $(\mathrm{m})$ alimentos receba $(\mathrm{m})$ treinamento(s) adequado(s) e contínuo(s) em matéria higiênico - sanitária, na manipulação dos alimentos e higiene pessoal, com vistas a adotar as precauções necessárias para evitar a contaminação dos alimentos.

$\S 1^{0}$ - Para fins de atendimento das disposições do caput, a direção do(s) estabelecimento(s) deverá(ão):

a) Efetuar treinamento de pelo menos 01(um) funcionário que exerça atividade ou ocupação na área de Alimentos, nos termos da Portaria SVS/MS n 326, de 30 de julho de 1997;

b) Instituir mecanismos que possam expandir os conhecimentos adquiridos pelo(s) funcionário(s) treinado(s) a todos os demais funcionários do(s) estabelecimento(s).

$\S 2^{\circ}$ - Fica $(m)$ excluído(s) da exigência contida na letra "a" do parágrafo anterior, todos os estabelecimentos que possuam em seus quadros funcionais, pelo menos 01 (um) Responsável Técnico para a 
Área de Alimentos, com formação escolar de nível superior e registro em Conselho Regional de Classe pertinente.

$\S 3^{\circ}-\mathrm{O}(\mathrm{s})$ funcionário(s) treinado(s), e o Responsável Técnico, quando for o caso, será(ão) o elo entre a Vigilância Sanitária e o(s) estabelecimento(s) fiscalizado(s) e a população em geral em suas demandas por qualidade e higiene sanitária.

Art.3 - A Secretaria de estado de Saúde do Distrito Federal através da Diretoria de Vigilância Sanitária, a seu exclusivo critério, credenciará órgãos ou entidades públicas ou privadas que operem na formação/treinamento de mão de obra qualificada na área de alimentos para fins de cumprimento das disposições do $\S 1^{\circ}$, letra "a" do art. $2^{\circ}$ desta Portaria.

$\S 1^{0}$ - Ficam dispensados do credenciamento para fins de cumprimento deste artigo, todos os órgãos e/ou entidades públicas ou privadas já credenciadas pela Secretaria de Saúde nos termos da Portaria, que, no entanto deverão ajustar o conteúdo programático, conforme ANEXO I, e a metodologia teórica e prática às disposições da Portaria SVS/MS n 326, de 30 de julho de 1997.

$\S 2^{\circ}-O$ treinamento exigido neste Diploma legal será obrigatório e condição necessária para a liberação do Alvará de Funcionamento previsto no art. 148 do Regulamento aprovado pelo Decreto 8386/85 de janeiro de 1985 , que neste caso deverão apresentar Certificado de Responsabilidade Técnica ou Carteira de Identificação Profissional emitido por Conselho Regional de Classe pertinente.

$\S 3^{\circ}$ - O treinamento exigido nesta Portaria será atestado através de "CERTIFICADO DE TREINAMENTO DE MANIPULADOR DE ALIMENTOS", de uso e caráter pessoal do funcionário treinado, que deverá conter a freqüência, carga horária de 40 (quarenta) horas 
para treinamento ou de 20 (vinte) horas para reciclagem bi-anual, e a avaliação de aprendizagem.

$\S 4^{\circ}$ - Além dos dados pessoais, o certificado deverá conter o símbolo da Diretoria de Vigilância Sanitária da Secretaria de estado de Saúde do Distrito Federal e do órgão ou entidade que ministrou o treinamento, devidamente assinado pelos mesmos, e a expressão em local destacado e visível: "Este Certificado tem validade de 02 (dois) anos a contar da sua emissão e deverá ser afixado em local visível no estabelecimento, sob pena de multa".

$\S 5^{0}$ - O Certificado deverá ser plastificado ou exposto em quadro próprio, em local visível do público usuário e consumidor, de forma a preservar sua integridade e durabilidade dentro do seu período de validade.

Art. $4^{\circ}$ - Competem a Diretoria de Vigilância Sanitária, fiscalizar o cumprimento desta Portaria.

$\S 1^{0}$ - O não cumprimento implicará em retenção da liberação do Alvará de Funcionamento, além da aplicação de penalidades previstas na Lei 6437/77 e demais legislações sanitárias vigentes.

$\S 2^{\circ}$ - As penalidades serão aplicadas diretamente ao estabelecimento infrator.

Art. $5^{0}$ - Esta Portaria entra em vigor na data de sua publicação. 


\subsection{ANEXO I}

Trata de conteúdo mínimo exigido para o treinamento de Manipuladores de Alimentos:

- Segurança no trabalho

- Higiene e aparência pessoal

- Higiene das mãos

- Higienização do ambiente

- Higiene dos utensílios

- Armazenamento e conservação de alimentos

- Noções de microbiologia

- Doenças transmitidas por alimentos

- Noções de Legislação Sanitária. 


\section{REFERÊNCIA}

BRASIL. MINISTÉRIO DA SAÚDE Portaria N³26 de 30/07/97Regulamento Técnico sobre as condições higiênico sanitárias de Boas Práticas de Fabricação para estabelecimentos produtores de alimentos. D.O.U de 01/08/97.

BRASIL. MINISTÉRIO DA SAÚDE RDC N² 275 de 21/10/02Regulamento Técnico de Procedimentos Operacionais Padronizados aos estabelecimentos produtores/industrializadores de alimentos e a lista de Verificação das Boas Práticas de Fabricação em Estabelecimentos produtores/industrializadores de alimentos.Republicada no D.O.U de 06/11/02.

BRASIL. MINISTÉRIO DA SAÚDE. Decreto-Lei 986, de 26/10/69.Institui Normas Básicas sobre Alimentos. 1969.

BRASIL. MINISTÉRIO DA SAÚDE. Informação, Educação e Comunicação. Uma estratégia para o SUS. Brasília: Assessoria de Comunicação Social, out, 1996. p.6.

BRASIL. MINISTÉRIO DA SAÚDE. Portaria 1428 de 26/11/93.Regulamento Técnico para Inspeção de Alimentos. D.O.U, seção $1, n^{\circ} 229$ de 2/12/93.

BRASIL.Constituição 1988: texto Constitucional de 05 de Outubro de 1988-Brasília: Senado Federal, Subsecretaria de Edições Técnicas, 2000.

BUSS. PM. Promoção da saúde e qualidade de vida. Ciência \& Saúde Coletiva 2000. 
CARVALHO. Guido Ivan. Comentários à Lei Orgânica da Saúde (Leis 8080/90 e 8142/90). Sistema Único de Saúde. São Paulo: Hucitec, 1995.

DHILLON, H. S. e PHILIP, L. Health promotion and comunication and community action health in developing countries, Genebra: World Health Organization, 1994, p.1-3.

GERMANO MIS, GERMANO PML, KAMEI CAK, et alii. Manipuladores de Alimentos: capacitar? É preciso. Regulamentar?... Será preciso ???- Higiene Alimentar, São Paulo: DPI, 2000; no 14, p. 18-22.

GERMANO MIS, RENCINAI, GERMANO PML -Grau de informação dos Manipuladores de Alimentos em pequenas e medias empresas na cidade de São Paulo. Higiene Alimentar. São Paulo: DPI, 2001 n$^{\circ} 15$ p. 94.

GERMANO, Maria Izabel Simões. Treinamento de manipuladores de alimentos:fator de segurança alimentar e promoção da saúde. São Paulo: Varela, 2003.

GUIA do empresário para o Sistema APPCC.2. (Série Qualidade e Segurança Alimentar). Projeto APPCC Indústria. Convênio CNI/SENAI/SEBRAE. Rio de Janeiro: SENAI/DN, 2000.

MAGALHÃES CS, GONÇALVES HSB. Manipulação de Alimentos: otimização de cozinhas industriais no município de SeropédicaRJ. Higiene Alimentar São Paulo: DPI, 2001 nº 15 p. 138.

ORGANIZAÇÃO PAN AMERICANA DE SAÚDE. HACCP: Instrumento Essencial Para a Inocuidade de Alimentos. Buenos Aires, Argentina: OPAS/ INPPAZ, 2001. 
PANETTA, José Cezar. Segurança dos alimentos, barreiras sanitárias e barreiras comerciais. Higiene Alimentar São Paulo: DPI, $2001 n^{\circ} 15$ p. 3.

PELCZAR JR.; Joseph Michael; CHAN, E.C.S.; KRIEG, Noel R. Microbiologia: conceitos e aplicações. São Paulo: Makron Books, 1996.

PROMOÇÃO da Saúde: Carta de Otawa, Declaração de Adelaide, Sundsvall, e Santa Fé de Bogotá. Tradução: Luis Eduardo Fonseca. Brasília: Ministério da Saúde, 1996.

QUEIROZ ATA, RODRIGUES CR, ALVAREZ GG, KAKISAKA LT. Boas Práticas de Fabricação "self-service" a quilo. Higiene Alimentar São Paulo: DPI, 2000; n 14: p. 45-49.

SANTOS, Saionara da Graça Freitas dos. Treinando Manipuladores de Alimentos. São Paulo: Varela, 1999.

SILVA JR., Eneo Alves. Manual de Controle Higiênico-sanitário em Alimentos. $2^{\mathrm{a}}$ edição. São Paulo: Varela,1996.

VALENTE Flávio Luiz Schieck. Do Combate à Fome à Segurança Alimentar: o direito à alimentação. 1999. Disponível em:<http://www.agora.org.br>.Acesso em:10 jan.2004. 